\title{
New Caledonia as the centre of origin of Parastephanellus Enderlein, with a phylogeny and description of the female of $P$. khogis Aguiar (Hymenoptera, Stephanidae)
}

\author{
ALEXANDRE P. AGUIAR ${ }^{1} \&$ JOHN T. JENNINGS ${ }^{2}$ \\ ${ }^{1}$ Universidade Federal do Espírito Santo, Departamento de Ciências Biológicas, Avenida Marechal Campos 1468, Eucalipto, Vitória, \\ ES, 29040-090, Brazil.E-mail: aguiar.2@osu.edu \\ ${ }^{2}$ Australian Centre for Evolutionary Biology and Biodiversity, and School of Earth and Environmental Sciences, The University of \\ Adelaide, SA 5005, Australia.E-mail: john.jennings@adelaide.edu.au
}

\begin{abstract}
The female for Parastephanellus khogis Aguiar is described, expanding the knowledge of the family Stephanidae in New Caledonia, previously centered on four species all known from single specimens. We also provide additional localities for $P$. khogis and discuss the morphological variation among the New Caledonian taxa, which seems to be morphologically conservative. A preliminary cladistic analysis including all stephanid species from New Caledonia and 63 species from other biogeographic regions suggests the origin of the genus Parastephanellus Enderlein in New Caledonia (lineage of $P$. delicatus Aguiar and P. mouensis Aguiar), and a recolonisation with taxa related to a possibly Australian lineage (P. khogis and $P$. sarramea Jennings).
\end{abstract}

Key words: biogeography, Pacific, Australia, New Zealand

\section{Introduction}

Aguiar \& Jennings (2005) provided the first records of Stephanidae in New Caledonia. They presented descriptions of four new species of Parastephanellus, together with a discussion on their possible relationships. All species were based on single specimens, but the authors predicted they should remain stable based on previously known variability of other Indo-Australian stephanids (Aguiar 2001).

With the discovery of the female of $P$. khogis Aguiar, as well as four other male specimens from two localities, both distant from the type locality, we were able to examine morphological variability for the first time, while also confirming the stability of the species proposed in the previous work. This also allowed an initial phylogenetic investigation and a discussion on the probable origin of New Caledonian stephanids.

\section{Methods, terminology and abbreviations}

Terminology, measurements and abbreviations for morphometric ratios follow Aguiar (2001), which includes the wing venation system modified from the Comstock-Needham system after Sharkey (1988). Observations on colour and sculpturing were made under an Olympus SZ40 stereomicroscope, with illumination from a 9W fluorescent desk lamp. Digital photographic images were produced with a Nikon Coolpix 885, adapted to the equipment described above, and then processed with AutoMontage software ver. 5.01.0005. Specimens are deposited in the Queensland Museum, Brisbane (QMBA). Label data for specimens and species also available at http://iris.biosci.ohio-state.edu/projects/stephanids. 